\title{
Non-Response in Probability Sample Surveys in the Czech Republic*
}

\author{
JIND ŘICH KREJČÍ ${ }^{* *}$ \\ Institute of Sociology, Academy of Sciences of the Czech Republic, Prague
}

\begin{abstract}
In this article the problem of survey non-response is examined with special reference to probability sampling in the Czech Republic. Non-response rates among Czech respondents in ISSP surveys between 1995 and 2005 were almost twice the rate recorded between 1991 and 1995 (25\%). Such trends point to a decline in the 'survey climate'. While non-contacts and refusals in surveys are a significant problem, issues relating to how fieldwork is undertaken are equally important. The large fluctuations in non-contact rates and the relative success of the Czech Statistical Office in attenuating non-response rates demonstrates that prudent surveying strategies can be effective. An examination of two waves of the European Social Survey (ESS) reveals both the problems and potential strategies available for response rate enhancement. In this respect, all survey designers face the dilemma of balancing the benefits of data accuracy with increasing logistical costs. Improvement in survey quality necessitates consideration of many issues and the ability to make sensible trade-offs between competing research objectives.
\end{abstract}

Keywords: survey research in the Czech Republic, response rates, non-response trends, fieldwork strategy

Sociologický časopis/Czech Sociological Review, 2007, Vol. 43, No. 3: 561-587

\section{Introduction}

This article deals with the issue of non-response rates in social survey research in the Czech Republic. It examines current trends and provides an in-depth analysis of this issue using the first two waves of the European Social Survey (ESS) in the Czech Republic.

The capacity of any quantitative analysis to provide evidence about social reality depends largely on the quality of the data gathered. Mass surveys, based

* The study was prepared as a part of the Grant Project No. 1N04192 supported by the Ministry of Education, Youth and Sports of the Czech Republic, and the Grant Project No. 403/06/1421 supported by the Czech Science Foundation. The author would like to thank Pat Lyons for very useful recommendations and his help with the English version of the paper and two anonymous reviewers for their valuable comments.

** Direct all correspondence to: Jindřich Krejčí, Institute of Sociology, Academy of Sciences of the Czech Republic, Jilská 1, 11000 Prague 1, Czech Republic, e-mail: jindrich.krejci@soc. cas.cz. 
on interviewing population samples, are among the most commonly used sources of data, and the quality of their analysis derives directly from how well these surveys represent their target populations. The level of representativeness depends on a number of factors. Key concerns are the level of coverage of the target population, the size of the sample, and the appropriateness of the sampling method used. Moreover, the degree to which researchers are able to reach and interview the selected respondents is of fundamental importance. Consequently, survey response rates are one of the key indicators of the quality of all survey data.

There are various ways of monitoring response rates, but essentially it is a matter of the ratio of the number of completed survey questionnaires received back and processed to the number of questionnaires distributed to eligible addresses in the sample. Complementary survey non-response is the failure to obtain data from the entire sample selected for interview. There are two main types of survey non-response. First, there is 'item non-response', where some respondents do not answer specific questions in an interview. Second, there is 'unit nonresponse', where specific individuals (or households) selected for an interview do not take part in the survey. This article will focus on unit non-response, as this is the most salient problem for all survey research.

The majority of surveys involve obtaining the voluntary cooperation of respondents. However, practical circumstances (e.g. the unavailability of the appropriate sampling frames, regulations pertaining to the protection of personal data, etc.) in many countries require the application of complicated sample designs. In addition different groups in the population maintain lifestyles that make it difficult to contact their members. There are also a number of organisational factors that can result in the failure to interview selected respondents. Therefore, achieving a satisfactory response rate can pose quite a problem. The successful processing of all the distributed questionnaires, that is, achieving a hundred-percent response rate, practically never occurs.

Based on experiences the prevailing wisdom among researchers is that since the mid-1990s there has been a dramatic decline in the response rates of sample surveys conducted in the Czech Republic. This view gives rise to serious concern about the future prospects of Czech social research. ${ }^{1}$ However, little scholarly attention has yet been devoted to this issue in the Czech Republic. Detailed examinations of response rates have been the subject of some reports prepared within the framework of individual research projects [e.g. Tuček, Gatnar and Krejčí 2000], but such texts, prepared for survey subscribers, are not often available to the wider public. There is also a book-length examination of the quality of political survey's estimates of voter preferences that draws attention to the issue of response rates [Krejčí et al. 2004]. However, to date there has been no

\footnotetext{
${ }^{1}$ This issue was discussed, for example, in the panel discussions 'What Methodology for Czech Sociology?' and 'Research Infrastructures' at the conference 'Czech-Slovak Sociology Days' in Prague, 10-12 May 2005. http://web.soc.cas.cz/cssd/.
} 
comprehensive study of the nature and potential impact of survey non-response on the quality of survey data generated within the Czech Republic.

The problems evident in Czech survey research do not always confirm the prevailing opinion of continual decline. There are also surveys with relatively high response rates, and, for example, the two Czech surveys conducted as part of the research programme of the European Social Survey (ESS) achieved substantially different outcomes. In the survey conducted in 2002-2003 the response rate was $43.5 \%$, while in 2004 the response rate during the fieldwork was $71.0 \%$.

The ESS is an international academic research programme that espouses strict methodological standards. Both waves of this survey conducted in the Czech Republic adhered to most of the methodological requirements stipulated by the ESS, but they differed in the emphasis put on applying procedures aimed at increasing response rates. In the context of the problems surrounding response rates, it is important to examine what factors may have contributed to generating such varied outcomes. However, owing to the marginal amount of attention devoted to the issue of response rates in the Czech Republic it is first necessary to look at the issue more generally and describe the current Czech situation.

Consequently, this article will focus on three key themes. In the first section, there will be a general overview of the issue of low response rates in survey research. This is followed by an examination of the non-response trend in the Czech Republic. The third section discusses differences in response rates in the first and second waves of the European Social Survey in the Czech Republic. In the final section some concluding remarks are made regarding the evidence presented.

\section{The problem of non-response in sample surveys}

A low response rate is often regarded as one of the main sources of variable variance and bias in mass survey estimates [see, e.g., Särndal and Lundström 2005; Dillman et al. 2002; Biemer and Lyberg 2003], though the linkage between nonresponse rates and survey errors is not direct and may even be absent [see Groves 2006]. There is a consensus among scholars and pollsters that response-rate trends have been declining, and that this fact poses one of the most serious problems affecting contemporary quantitative social science research [e.g., Bradburn 1992; Bogart 1987; Särndal and Lundström 2005: 11-15].

Two main reasons are most often cited as the cause of this decline in response rates. The first reason paradoxically stems from the boom in the research industry. The number of surveys undertaken each year has been increasing for decades. According to estimates in advanced industrial countries the majority of potential respondents have been surveyed, often several times, and the population could be described as 'over-surveyed'. People moreover have difficulty distinguishing between surveys and direct marketing, which competes with survey research by infringing on the privacy of respondents. The result is an overall in- 
crease in refusals. The second reason relates to changes in lifestyle, which make it increasingly more difficult to reach the respondents selected for interview and therefore cause an increase in non-contact rates.

\section{Non-response trends}

Steeh [1981] reports a large increase in the number of refusals in survey research in the United States between 1952 and 1979. This decline in response rates has subsequently been confirmed in numerous analyses focusing on different survey programmes in various fields of research and in individual countries. However, it is not easy to document general trends because there are big differences between survey methods and their consequences, and the situation varies also between countries and different research fields and topics. There have been few long-term research programmes based on a stable methodology that would enable a deeper evaluation of this phenomenon. Those that do exist do not encompass all fields of research and moreover their analyses have produced ambiguous results.

Several analyses of trends in response rates over time and cross-nationally have confirmed the existence of a general decline [Baim 1991; de Leeuw and de Heer 2002]. While other studies do not dispute the fall in response rates in the past, they do not confirm the continuity of the decline [de Heer 1999; Smith 1995; Steeh et al. 2001; Groves and Couper 1998: 156-172]. According to practitioners from survey agencies [e.g. Sheatsley 1987] it is still possible to attain high response rates, but it requires more effort and higher costs in organising the research. This observation can be readily seen in the outcomes of surveys that emphasised the use of a rigorous data quality methodology, for example, surveys conducted by statistical offices or the General Social Survey in the United States [de Heer 1999; Groves 2004: 145-153; Smith 1995]. These studies regularly achieve a response rate of at least $70 \%$ in countries where a significant fall in response rates has been registered.

However, there tends to be enormous differences between outcomes when different methodologies are used. The Council for Marketing and Opinion Research (CMOR) conducts the 'Respondent Cooperation and Industry Image Study' and monitors the response rates of many different surveys. ${ }^{2}$ Among other things, its studies reveal that the response rates of commercial telephone surveys conducted in the United States are often below 25\%. Steeh et al. [2001] studied the response rate of commercial surveys conducted using the 'random digit dialling' (RDD) method. According to their findings, in the 1960s and 1970s there was a sharp increase in non-response and especially in refusal rates. This trend subsided in the 1980s and 1990s, and now survey response rates appear to be stable. However, the nature of non-response has also been changing, to the detriment of measurement accuracy, owing to an increase in overall non-contact rates and a decrease in refusals, especially in metropolitan areas, and other reasons.

\footnotetext{
${ }^{2}$ See the research section of the CMOR website: http://www.cmor.org/.
} 
Inference in surveys with non-response and treatment of the problem

From the perspective of statistical inference, survey non-response has an impact on point estimates in terms of bias and the inflation of variance and bias in the estimators of precision [Dillman et al. 2002: 4-6; Särndal and Lundström 2005; Groves 2004: 158-159]. However, it must be stressed that estimations of error caused by non-response are theoretical, and any exact assessment of the impact of lower response rates is usually problematic. This is because the non-response error does not stem from the non-response rate as such, but is the result of the extent of the differences between the attitudes and characteristics of respondents and non-respondents with respect to the measured phenomenon. At the same time, relevant data on non-respondents are by definition missing. Groves [2004: 133] summarises this approach with the following equation.

\section{RESPONDENT VALUE $=\begin{aligned} & \text { FULL SAMPLE VALUE }+(\text { NON-RESPONSE RATE }) x \\ & (\text { RESPONDENT VALUE }- \text { NONRESPONDENT VALUE })\end{aligned}$}

If the attitudes of respondents and non-respondents are the same then a low response rate does not matter. Several empirical studies confirm this fact, describing situations when higher non-response did not lead to higher biases [e.g. Keeter et al. 2000; Merkle and Edelman 2002: 253-255; Groves 2006]. However, many analyses have shown that response rates are correlated with population characteristics and thus also associated with biases of estimations. On the other hand, the impact of these correlations does not usually invalidate the results of a survey and can be often corrected by weighting [e.g., Stoop, Iedema and Louwen 2000; Keeter et al. 2000]. These relationships also depend heavily on the topic of research [e.g. Zaletel and Vehovar 1998], and they do not affect all variables equally [e.g. Joye 2004], so the impact of non-response on survey data quality cannot be generalised.

While non-response error cannot be ignored, it is often not possible to make any reliable estimate of its size. Although many researchers consider the sample survey method to be relatively robust, non-response has the potential to be the source of some unpleasant surprises. One of the consequences of this lack of transparency is that non-response error is not usually taken into account in survey estimates and statistical tests. However, a low response rate is often regarded as sufficient reason for commissioning agencies, researchers, journal editors, and other users of data to question the accuracy of survey research results. This is reflected in the substantial effort invested in developing and applying methods aimed at increasing response rates and reducing non-response error.

Statistics offer two basic approaches to addressing non-response: imputation and weighting. Imputation means substituting the values for missing units with estimates developed on the basis of auxiliary information obtained in the research or from other sources. But in the case of unit non-response this is often not feasible. The most frequently used weighting procedures are based on com- 
paring the socio-demographic characteristics of surveys with those published in official statistical sources. On the basis of observed differences weights are assigned to cases in the data file with the objective of matching the profile of the sample dataset with the known composition of the target population. However, Joye [2004] has shown that other variables, such as participation and social integration, which have only an indirect relationship to the 'objective' criteria normally used in weighting, may also be strongly correlated with the propensity toward non-response.

Post-fieldwork adjustments of survey data can reduce the level of error, but such procedures cannot fully make up for data that are missing. However, there are a number of methods used to improve response rates that are applied in the survey preparation phase and in the course of data collection. Among the most frequently used strategies [Biemer and Lyberg 2003: 91-115] are advance letters of introduction, providing incentives to respondents, increasing the number of contact attempts and call-backs, adopting techniques of refusal conversion, adapting the timing of fieldwork to match respondents' lifestyles, constructing questionnaires with due regard to respondent burden and likely interest in the content of the survey interview, improving interviewer selection and training, and utilising mixed modes of interviewing, etc.

It should be always borne in mind that the objective here is not only to increase the response rate but also and primarily to reduce non-response error. Some methods can help increase response rates, but they can also have the unintended consequence of increasing the level of bias in a survey. Techniques of refusal conversion, for example, do not help if the main source of bias is the low representation of hard to reach groups within the population. Similarly, incentives to encourage respondents to participate must be applied cautiously, because different groups of the population respond to 'prodding' in different ways. It should also be remembered that the key issue of survey data quality is efficiency. In short, efforts devoted to ensuring survey accuracy need to be tempered by cost considerations. Therefore, careful thought needs to be given to the kinds of remedial methods implemented.

The response rates are affected by a number of mutually inter-connected factors. Some of them, such as the social context and the respondent's lifestyle, are beyond the researcher's control, but they are important sources of the potential biases caused by non-response. Addressing other factors, such as the performance of interviewers, is not just a task that lies within the scope of how a single survey is organised, but is often the result of long-term systematic work. Successful strategies for reducing non-response error are therefore usually based on the combined use of various methods, the selection of which depends on external circumstances. Fortunately, there is currently a substantial amount of literature available on the effects associated with the use of various surveying methods, and theories on survey participation [e.g. Groves and Couper 1998] provide the necessary conceptual foundations for assessing the strategies aimed at reducing non-response. 


\section{Non-response trends in probability surveys in the Czech Republic}

Before the Velvet Revolution in 1989 very specific conditions existed in Czechoslovakia for conducting sample surveys. Social research was controlled by the totalitarian regime. As a result, relatively few surveys were conducted and their thematic focus was restricted. Interaction with respondents took place in an atmosphere of suspicion, where overt expressions of loyalty to the regime were obligatory. Given these special circumstances it is not surprising that the decline in response rates described in many Western countries was not witnessed in Czechoslovakia during the 1970s and 1980s.

\section{Survey climate}

After 1989 survey research underwent a fundamental change for a number of reasons. The number of public opinion surveys grew substantially, and a new and large sector of market research emerged. Moreover, the country became involved in international academic research programmes. At the same time the external conditions in which research has been conducted changed in distinct ways [see Krejčí 2004].

First, at the end of 1992 Czechoslovakia was divided into two separate states, the Czech Republic and Slovakia. This led also to the gradual division of research structures. Second, probability sampling has become significantly more complicated. Since 1993 researchers have not had access to the Central Population Register. Since 2001 the database of households, which is maintained by the Czech Statistical Office, has only been open to researchers working on official statistical surveys. The quality of samples based on the commercial database of addresses from SIPO, a service through which the public can make regular bill payments, is now questionable given the widespread availability of alternative means of making payments. These constraints resulted in a lack of quality sampling frames, which complicates the design of samples and increases costs. Third, since 2002 strict legislation has applied to the protection of personal data. This further complicates the process of sampling, collecting, and processing data.

However, not all changes to the survey climate have been institutional in nature. Lifestyle changes stemming from the political and economic transition process have also had an important impact, not only on the topics examined in survey research, but also on the manner in which the research is undertaken. One example of this process is that some population sub-groups have become harder to contact. Rising crime rates have made it more difficult for interviewers to establish contact with increasingly wary respondents. The main entrances of residential buildings now tend to be locked and the initial moment of contact occurs through an intercom. It is also harder to gain the public's trust. The rise in the number of marketing activities has contributed to a greater emphasis on protecting the privacy of individuals. 
Negative experiences from the totalitarian past have resulted in a prevailing fear about the abuse of personal information on individuals and households. For example, the Czech survey on Social Stratification in Eastern Europe after 1989 became the target of a massive assault from the media. During the course of data collection in 1993 researchers were accused of preparing a database of information on individuals for use in an anti-reform plot. This led to a decline in the response rate of this survey. Even official statistical surveys such as the 2001 Census have been accused of misusing information, and the need to collect such data at all has been called into question.

\section{Survey non-response}

These changes have been accompanied by unfavourable developments in response rates. Despite the lack of any systematic research on outcome rates the prevailing wisdom within the Czech survey-research community in this respect may be summarised as follows:

(a) In the mid-1990s there was a sharp increase in non-response rates in Czech surveys.

(b) In the following decade this trend accelerated.

Unfortunately, it is not possible to make an extensive and in-depth analysis of the trends for three main reasons. First, the examined period is not long, because social research has only been developing freely in the Czech Republic for a short time - less than two decades. Second, there are few publicly accessible probability surveys that allow a detailed monitoring of non-response rates. Many important surveys have been based on quota samples and do not provide relevant data on response rates. ${ }^{3}$ Third, the circumstances described above also mean that there is no long-term survey that has not been affected by significant changes in its methodology, and thus identifying the causes of non-response can be difficult. Nevertheless, there is still enough evidence to evaluate the validity of the above-mentioned conviction generally shared by experts.

Standards for publishing information on response rates have not been generally established in the Czech Republic. Consequently, such information is not

\footnotetext{
${ }^{3}$ The number of refusals can be reported also for quota samples, but it provides only limited information about the non-response problem and is incomparable with outcomes of probability surveys. At the same time, in quota surveys interviewers are less motivated to interview hard to reach and less compliant members of the population, and the potential for error is consequently even greater. The higher level of obscurity of the non-response problem in quota surveys and its possible risks is one of the reasons why quota samples are a less preferred survey method [e.g. Kaase 1999]. On the other hand, for example, Groves shows that the problem is more complicated and with respect to non-response in both probability and non-probability sample surveys, researchers are required to deal with the same set of methodological questions, but they have different resources to answer them [Groves 2006: 667-668].
} 
available for a number of surveys. In other cases response rates are overestimated because not all types of non-response are included. For example, there is a tendency to ignore interviewer failures, and at some agencies these are the source of as much as one-third of all non-responses. Sometimes only refusals are taken into account, so what is really being reported is the 'cooperation rate'. If such information is used in the place of the total response rates, which happens regularly, the result is an underestimation of the risk of biased inferences resulting from non-response error. However, concealing or providing incomplete information on response rates is an infringement of professional standards and against the rules of the international associations such as WAPOR, ESOMAR and EFAMRO [see Smith 2002], and SIMAR, the professional market research association in the Czech Republic. ${ }^{4}$

Therefore, only surveys that are publicly accessible and whose metadata include a detailed breakdown of outcomes allowing a comparison of response rates have been used. Calculations of survey response and non-response rates are based on definitions specified by AAPOR [2006]. All types of non-response are taken into account, except incorrect or unoccupied addresses and administrative errors connected with the sampling process.

Figure 1 presents non-response trends in the area of academic research. These are Czech surveys conducted as part of international research programmes, and I have used them because they provide all the necessary information for analysis. All surveys are based on probability sampling of individuals from the general adult population and face-to-face interviews.

However, the surveys differ in terms of their research topics and methodological details. (More information is given in the appendix.) The majority of these surveys were conducted as part of the ISSP and were organised by the Institute of Sociology of the Academy of Sciences of the Czech Republic, so there are a number of similarities in the methods used and in the background of the surveys. ${ }^{5}$ In the case of Czechoslovak surveys, only the data for the Czech part of the survey are presented.

Research surveys carried out at the start of the 1990s exhibited in comparative terms a relatively low level of non-response. The Social Stratification in Eastern Europe (SSEE) study of 1993, which had the highest rate of non-response

\footnotetext{
${ }^{4}$ The World Association for Public Opinion Research (WAPOR), the World Association for Marketing Research (ESOMAR), the European Federation of Associations of Market Research Organisations (EFAMRO), and the Association of Market and Opinion Research Agencies (SIMAR). The main Czech research agencies are members of at least one of these organisations.

5 The International Social Survey Programme is a long-term comparative research project, in which each year a survey with an identical module of questions is conducted in each of the participant countries. As of 2006 there are 41 member countries. The Czech Republic has been conducting the ISSP survey since 1992; all Czech ISSP surveys are based on probability samples. See the ISSP website: http://www.issp.org.
} 
Figure 1. Non-response in selected academic surveys in the Czech Republic, 1991-2005 (\%)

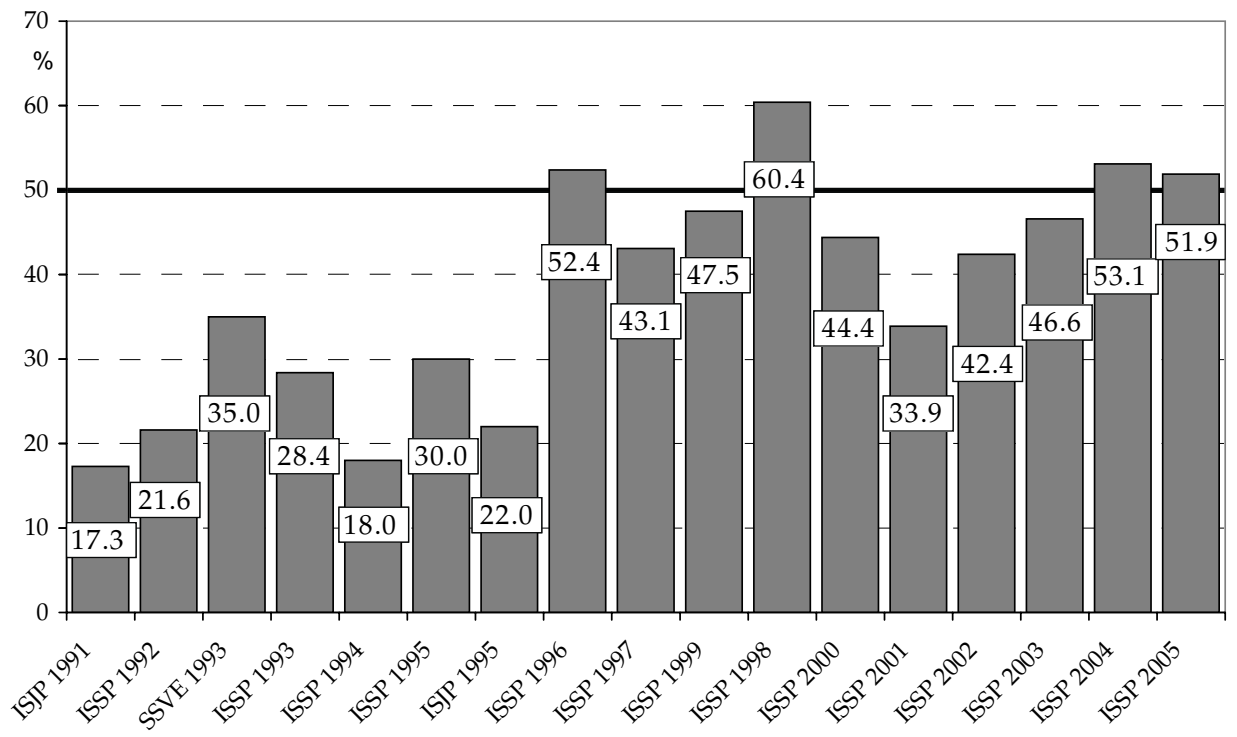

Note: For additional information on surveys see the appendix. Non-response does not include ineligible addresses, i.e. out-of-sample and vacant housing units and non-residential addresses.

Source: Sociological Data Archive, Institute of Sociology AS CR.

among surveys conducted in the first half of the 1990s, was accompanied by a negative media campaign. As a result an initially low non-response rate increased dramatically to a final overall average of 35\% [Matěju 1993]. Non-response rates in other contemporary surveys fluctuated between $17 \%$ and $30 \%$. This outcome is comparable to the non-response rates recorded in the General Social Survey (GSS) in the United States, which in the years between 1975 and 2004 ranged from $17 \%$ to $30 \%$ [Davis, Smith and Marsden 2005]. However, with the exception of the SSEE, the outcomes in this period were significantly better than the German Allbus study, which had a non-response rate of 32-48\% between 1988 and 1995 [Allbus Datenservice 2007]. It should be noted that the GSS and Allbus are among the most important social-science surveys in their respective countries and both put emphasis on the use of a rigorous methodology.

Although some of the differences in response rates can be ascribed to methodological differences and differing survey topics, Figure 1 clearly shows that there was a substantial increase in the non-response rate in the mid-1990s. In surveys conducted after 1995 the rate of non-response did not fall below 30\%. Regrettably it was not unusual for non-response rates to exceed $50 \%$. The data presented in Figure 1 confirm the view expressed within the Czech survey re- 
Figure 2. Refusals, non-contacted and other unproductive interviews in Czech ISSP surveys, 1997-2005 (\%)

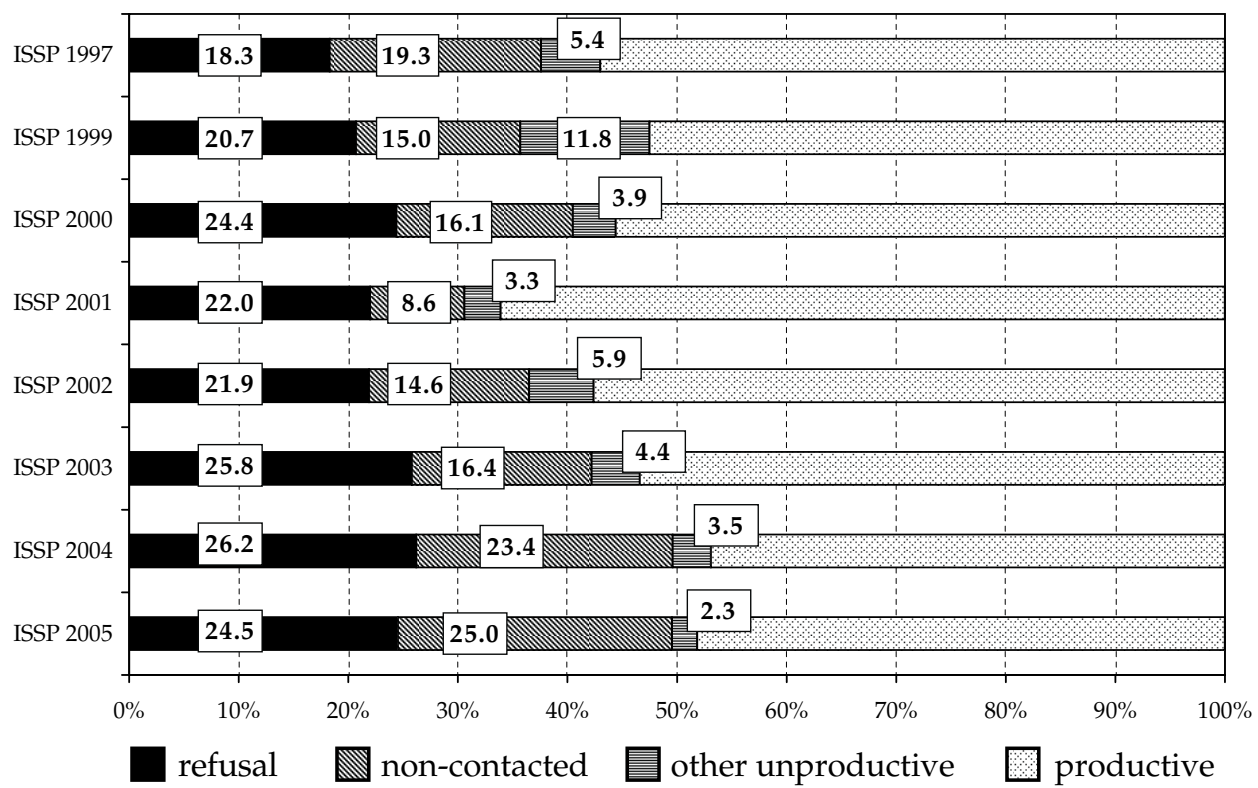

Note: For additional information on ISSP surveys see the appendix. ISSP (1998) is not included owing to missing information on non-contacts.

Source: Sociological Data Archive, Institute of Sociology AS CR.

search community that in the 1990s there was indeed a sharp decline in response rates. In fact, our data reveal that after 1995 response rates never exceeded 70\%. Equally important is the fact that the belief that there had been an increase in the non-response rate after 1996 is not supported by the evidence examined.

In Figure 2, which provides a more detailed view of the ISSP surveys conducted between 1997 and 2005, we can see that the differences in response rates are not just caused by changes in the number of refusals and thus the willingness of the public to cooperate, but also stem from differences in the number of noncontacts and other forms of non-response. It is interesting to note that non-contacts do not exhibit a consistent trend, and it would therefore be dubious to try to explain their variations as resulting from external causes alone.

The figures for other forms of non-response are also relatively high. For example, in the ISSP 1999, which had the highest non-response rate, the main source of the problem was failures on the part of the interviewers [STEM 1999]. We can therefore infer that the reason for the considerable differences in response rates, rather than being evidence of a negative trend in the Czech public's willingness to cooperate, are the result of other factors, such as the performance of the 
Figure 3. Non-response in the quarterly Labour Force Survey in the Czech Republic, 2002 q1 to 2005 q4 (\%)

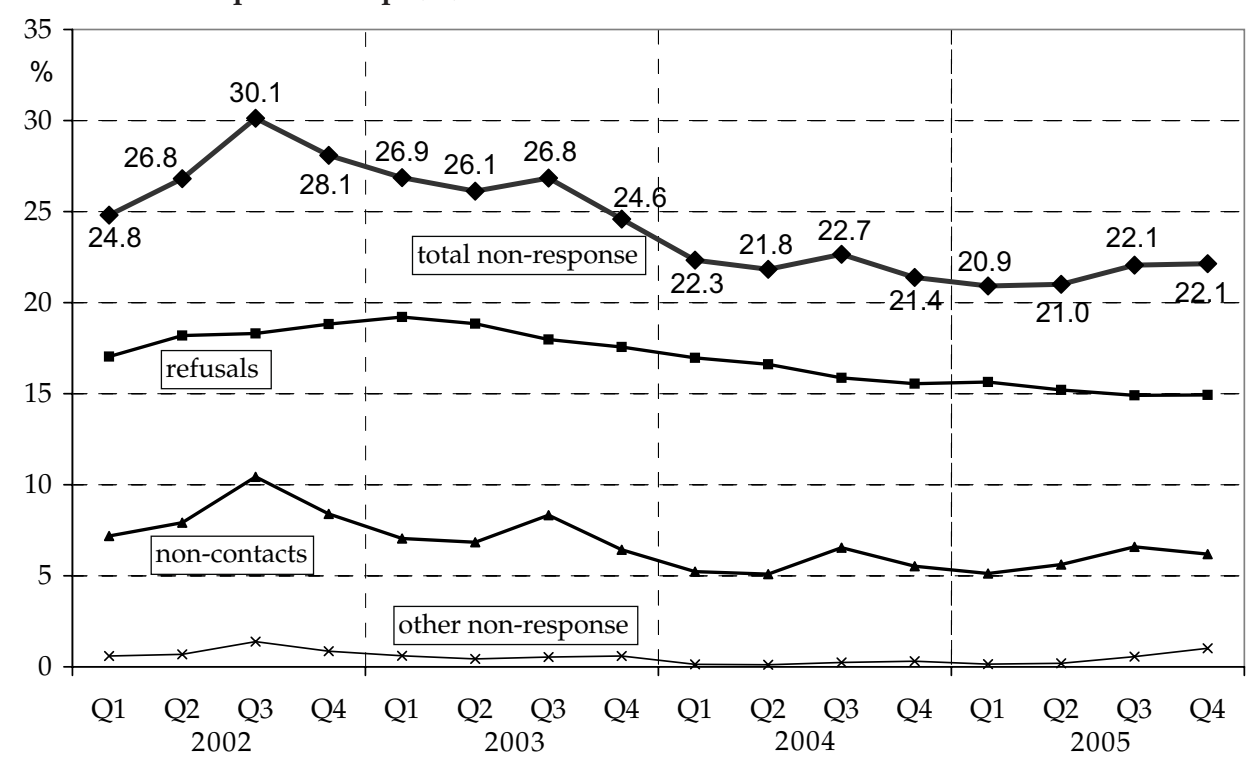

Source: Labour Force Survey, Czech Statistical Office.

fieldwork agency, the methodology used, timing, and other conditions affecting data collection.

An important factor is certainly the survey topic. For example, the technical report for the ISSP 1996 on 'The Role of the Government' explains the low response rate as a result of the unwillingness of respondents to answer questions on political topics in a period following two national elections [STEM 1996]. Also, the response rates for the ISSP 1998 on 'Religion' were affected by the timing of data collection - during the summer holiday period - and by the topic of the research itself. This is evident from biases in the socio-demographic profile of the sample. There was an over-representation of respondents claiming to belong to a specific religious denomination, a higher than expected level of religiosity, and a relatively high number of Christian Democrat (KDU-ČSL) voters.

It is appropriate at this point to briefly examine an official statistical survey. Here we will look at the Czech Statistical Office's quarterly 'Labour Force Survey' (LFS - Výběrové šetření pracovnich sil) which is a large household survey (of approximately twenty-six thousand, i.e. $0.6 \%$ of dwelling households in the Czech Republic) that examines the position of respondents in the labour market, labour mobility, economic activities in the population, social status, general economic conditions, and other related topics. The results are used for the purposes of official statistics and are available on the website and in the publications of 
the Czech Statistical Office and Eurostat. ${ }^{6}$ The methodology used corresponds to the requirements of the ILO and Eurostat and is based on a random sampling of households ${ }^{7}$ and face-to-face interviews.

Figure 3 presents data from the LFS for the period since the last major revision in survey methodology in 2002. Unfortunately detailed information on outcome rates are available only since 2002; between 1992 and 2001 only total non-response rates were reported and therefore this period cannot be included in the figure.

One striking feature of this data is that non-response rates in the LFS are considerably lower than in the academic surveys shown in Figure 1. The LFS non-response rates fluctuate between $20 \%$ and 30\%. This evidence demonstrates that in the current survey climate in the Czech Republic it is possible to attain relatively high survey response rates.

Of course, in this case, we can also suppose some impact from the 'sponsorship effect', that is, that the willingness to cooperate depends on the data collection agency and the purpose of its activities. Consequently, official statistics often have lower non-response than academic surveys, and academic surveys commonly have lower non-response than commercial polls [Groves and Couper 1998]. On the other hand, the differences in outcomes do not just stem from refusals, which are only an effect of the willingness factor. Figure 3 also clearly reveals a general trend toward decreasing non-response rates, both in the case of refusals and non-contacts. We can therefore conclude that the data at our disposal do not support the prevailing conviction that all survey response rates are declining in the Czech Republic.

\section{The methodology used in the ESS I and ESS II in the Czech Republic and their response rates}

ESS is a biennial academic study of changing social, political, and economic attitudes within Europe. A total of twenty-six countries took part in the first two waves of research. The project has an elaborate organisational structure that is partly funded by the European Commission and the European Science Foundation. However, the surveys conducted in the individual participant countries are sponsored from national sources. Detailed information on the project, along with data and documentation for particular national surveys, are available on the official ESS website. ${ }^{8}$

${ }^{6}$ Czech Statistical Office: http://www.czso.cz; Eurostat: http://ec.europa.eu/eurostat.

7 The Czech Statistical Office manages its own database of households, which is organised as the outcome of a census and is used for sample surveys as a sampling frame. Before 2001 this database was used also in a number of academic surveys. The major problem is connected to the recency of the database, as the number of wrong addresses rises with the time passed since the census. The last Czech census was organised in 2001.

${ }^{8}$ http://www.europeansocialsurvey.org. 


\section{The European Social Survey (ESS)}

The key objective of the ESS is to build up a database of time series and internationally comparable indicators that can be easily accessed by all researchers, including project coordinators, under the same conditions. The ESS is therefore one of the most important infrastructures in European social research. It uses a general model, which is applied repeatedly in all research waves, and it contains a large methodological component and specific thematically defined modules.

The ESS strives toward standardisation and toward reducing the differences in research design and fieldwork procedures in participant countries, and it demands adherence to the specific survey parameters [ESS 2002, 2004]. These parameters include, for example, full coverage of the residential population aged 15 and over, use of strict probabilistic methods of sampling at all stages, a minimum effective sample size of one thousand five hundred respondents, a target response rate of $70 \%$, and a target non-contact rate of 3\%. The Central Coordination Team must approve the surveying methodology proposed by national survey teams.

In order to get an idea of the rigorous surveying protocols the ESS insists on, let us examine for a moment their recommendations for achieving high response rates [Philippens and Billet 2004; Philippens et al. 2003; Pleyser and Billet 2006].

- The fieldwork period should last at least one month

- There should be briefing and training of all interviewers

- Interviewer workloads should be limited (i.e. a maximum of 24 interviews per interviewer)

- Face-to-face data collection should be used

- At least four calls should be made on different days and at different times when trying to interview difficult to reach potential respondents

- In countries with no individual level sampling frames all first contacts for interviews should be made face-to-face

- Attempted interviews should be spread over at least two different weeks

- No substitution of units selected for interview at any stage

- Refusal conversion strategies should be used

- Detailed contact forms should be used

- Detailed monitoring of the data collection process must be provided

- Quality control checks of interviews completed should be adopted

However, it should be noted that national ESS survey coordinators have the option of proposing strategies for reducing non-response rates. In this respect, the ESS recommends using advance letters of introduction, toll-free telephone numbers for potential respondents to contact, selecting experienced interviewers, extra training of interviewers in response-maximisation techniques and doorstep interactions, implementing refusal avoidance and conversion techniques, re-con- 
tacting 'soft' refusals and 'indecisive' non-contacts, and the use of appropriate respondent incentives and other strategies.

\section{The European Social Survey in the Czech Republic}

Two waves of the ESS have been conducted so far in the Czech Republic: the ESS I in 2002-2003, and the ESS II in 2004. Like the ISSP, both surveys were organised through the Institute of Sociology of the Academy of Sciences of the Czech Republic. Most of the main methodological features prescribed by the ESS were observed. It is important at this point to outline five key areas of difference between the successive waves of the ESS.

\section{a) Fieldwork agencies}

Data collection in the first wave of research was conducted by STEM and in the second wave by SC\&C. Both companies are among the leading research agencies in the Czech Republic. Both companies have long-established, extensive interviewer networks. Moreover, both have conducted numerous probability surveys and have participated in a number of academic research projects, including highlevel international research programmes. ${ }^{9}$

\section{b) Sampling method}

Probability sampling or more specifically stratified multistage sampling was used in both waves, but the specific methods applied differed. In the ESS I, the sampling frame used by STEM was derived from the SIPO database. ${ }^{10}$ The stratification factors were communities and region. In the first step, the communities were selected, then the SIPO addresses (i.e. households), and in the third step individual respondents were selected with the aid of a Kish grid.

\footnotetext{
${ }^{9}$ For example, STEM undertook the ISJP $(1991,1995)$ and the ISSP $(1992,1996,1997,1999)$, while SC\&C was responsible for the ISSP $(1998,2000-2004)$, SIALS (1998), and the EVS (1999).

${ }_{10}$ The SIPO is a special payment system that in communist Czechoslovakia provided services that are in other countries often provided by banks, and it is still widely used today. Regular household bill payments, especially utility payments, TV and radio fees, telephone bills, and bills for other services, are grouped into a single bill and are paid through the post office into the relevant accounts. The continuous updating of registered addresses using the SIPO system initially represented an almost comprehensive resource for household sampling with an estimated coverage of up to $98 \%$ of Czech households (in the first half of the 1990s). There now exist other means and systems of payments, and the number of addresses in the SIPO is much lower than the number of households recorded in official statistics, and therefore the quality of this database source is questionable.
} 
In the ESS II the sampling frame used was the UIR-ADR address register, i.e. an electronic database of all buildings in the Czech Republic. ${ }^{11}$ The register is regularly updated and identifies buildings on individual streets (where streets can be identified) within all towns and villages. Sampling proceeded in four stages: 1) communities, 2) streets or small communities, 3) household units, and 4) individuals. The unique character of this sampling frame produced a complicated research design. For example, the database did not provide information on the number of household units per street, only the number of buildings, so in the third step of sampling a list of household units in selected streets and small communities had to be drawn up first, following a preliminary interviewer appraisal of the target street.

\section{c) Financing}

The method of financing in each round of the survey differed. In the first wave, the Ministry of Education, Youth and Sport provided a grant for the research under the International Non-Governmental Organisation (INGO) programme. In the second wave, the Czech Science Foundation provided funding. In the first wave the funds were only released at the end of 2002 and less was provided than had been planned for in the approved grant. This had a serious impact on the preparation and the course of data collection, the performance of which had been sub-contracted. As a result, some of the techniques that had been planned could not be used owing to time and financial constraints. In addition, data collection dragged on into 2003, and cooperation with the fieldwork agency also proved to be complicated.

\section{d) Fieldwork timing}

For the financial reasons mentioned earlier, data collection in the ESS I was conducted, contrary to the instructions of the research coordinating team, in two stages: from 21 November to the end of December 2002, and from 2 January to 9 March 2003. In the ESS II, data collection was conducted within the required time frame and took place in a single period, between 1 October and 13 December 2004.

e) Methods for enhancing the response rate

In the ESS I, owing to financial and time constraints, it was not possible to carry out the special training for interviewers that had been planned or to apply specific strategies designed to enhance response rates. It was therefore necessary to rely on the standard training provided to interviewers by STEM. The interviewers visited the sampled addresses personally and advance letters of introduction

\footnotetext{
${ }^{11}$ The Register, organised by the Ministry of Labour and Social Affairs, is publicly acces-
} sible on the Web. 
were used. Special procedures for refusal conversions were not applied beyond the regular methods used by STEM interviewers. Also, no special incentives were used. Remuneration for interviewers paid for the return of completed questionnaires was below the average for the tasks they performed. The methodology proposed a minimum of six attempts at contacting respondents on various times and days in the week.

However, some of these procedures were not followed. For example, after data collection was completed it was discovered that fewer than four attempts had been made at $46 \%$ of the non-contact addresses. A large number of contact forms were completed incorrectly, and it was difficult to reconstruct how the fieldwork had proceeded [see also Phillipens et al. 2003].

In the ESS II, approximately three hours of special training was provided to interviewers. Emphasis was placed on ensuring that the contact forms would be filled in properly. Only experienced interviewers from SC\&C who have regular training in techniques for establishing contacts with respondents and maximising refusal conversions carried out the interviews. Advance letters of introduction were used, and the households contacted were provided with the agency's telephone number. Payments to interviewers for completed and incomplete questionnaires differed significantly. They received higher than usual remuneration for their work and were rewarded with a bonus for achieving high response rates $(\geq 70 \%)$. At the same time emphasis was put on monitoring the interviewers' work. More than $30 \%$ of the interviews were supervised and 572 sample units were back-checked (except for 15 cases in which back-checks were not achieved the outcomes from the fieldwork were confirmed). To elicit good will the respondents were given a large package of coffee or tea and a calendar. In addition, at last four attempts were made to contact respondents. Data collection was controlled on an ongoing basis and 'soft' refusals and some non-contacts were targeted for additional 'conversion' visits by interviewers in order to reduce non-response rates to below $30 \%$.

\section{f) Evaluation}

In formal terms the ESS I used a simpler and cleaner sampling method than the ESS II. The procedure used to collect data was organisationally less demanding and there was hence less room for error. Nevertheless, as noted above, the sampling frame derived from the SIPO database is problematic given the probably limited population coverage. There are therefore problems in assessing the impact of sampling design effects on total survey error for the ESS I. In contrast to other Czech academic surveys, such as the ISSP, the ESS I was organised without any specific techniques to enhance the response rate. Unsurprisingly, this led to problems with the interviewer team, many of whom had difficulties completing the contact forms correctly.

In the ESS II no satisfactory sampling frame was available. Consequently, a complicated sampling procedure was used that placed high demands on organis- 
ing the research. For example, as noted above, the breakdown of dwelling units on selected streets had to be obtained before interviewing commenced. However, there was one key advantage to performing the somewhat onerous task of creating a 'fresh' sampling frame - the interviewers' efforts to contact respondents were not complicated by the problem of incorrect addresses. Moreover, the interviewers underwent additional training specifically for the ESS II project. According to the SC\&C manager in charge of the project the higher response rate achieved in the fieldwork stemmed from a combination of three main factors: i) the use of the appropriate respondent incentives, ii) the higher rewards offered to interviewers, and iii) the elaborate system implemented to explain the purpose of the survey to the respondents.

At this point it should be stressed again that effort and particular methods for enhancing response rates can also have a negative influence on survey biases. For example, the positive and negative effects of respondent incentives on total survey errors are largely examined and discussed in analytical literature, ${ }^{12}$ giving bonuses to interviewers for high response rates can encourage them to falsify interviews, conversion methods can have problematic impact on quality of data, etc. Therefore only well-considered strategies can reduce risks and have a positive effect on total survey error. Finally, it should also be mentioned that in many cases the relationship between stronger efforts to enhance the response rate and a reduction of total bias was confirmed [e.g. Olson 2006; Lynn et al. 2002].

\section{The effects on response rates}

A comparison of the outcome rates in both waves of the Czech ESS surveys is presented in Table 1. Row $\mathrm{O}$ of this table shows the data on total response rates calculated in accordance with current AAPOR standards [2006]. It is immediately obvious that the response rate for the ESS II was 12.2 percentage points higher than the response rate for the first wave of the ESS. This is a substantial difference, which stems from the fact that on most criteria presented in Table 2 the ESS II was more effective, e.g. had a lower rate of refusals. While the effectiveness of the ESS II in reducing non-response is dramatic, the response rate of $55.5 \%$ is similar to the achievements of other academic surveys undertaken in recent years (e.g. ISSP 2000-2003, see Figure 1.) where no specific strategy for attaining a higher response rate was used.

The picture changes when we look at the composition of non-responses. In the ESS II questionnaires were not distributed at all to almost one thousand two

\footnotetext{
12 A review of this literature can be found, for example, in Stoop [2005], who summarises that 'the evidence from many studies...is not entirely conclusive', but 'most researchers seem to agree that a small incentive is generally seen as a nice gesture, both by interviewers and respondents, that a large incentive is not necessarily more effective than a small one, and that incentives do not have a detrimental effect on survey quality' [ibid.: 94].
} 
Table 1. Response and non-response rates in ESS surveys in the Czech Republic

\begin{tabular}{|c|c|c|c|c|c|}
\hline & & \multicolumn{2}{|c|}{ ESS I 2002/2003 } & \multicolumn{2}{|c|}{ ESS II 2004} \\
\hline & & $\mathrm{N}$ & $\%$ & $\mathrm{~N}$ & $\%$ \\
\hline A. & Total issued sample & 3330 & 100.0 & 5531 & 100.0 \\
\hline B. & Wrong addresses & 191 & 5.7 & 66 & 1.2 \\
\hline C. & Respondent deceased/moved & 0 & 0.0 & 8 & 0.1 \\
\hline D. & Sampled addresses not used & 0 & 0.0 & 1196 & 21.6 \\
\hline E. & $\begin{array}{l}\text { Eligible addresses used for fieldwork: } \\
\text { A- }(B+C+D)\end{array}$ & 3139 & 94.3 & 4261 & 77.0 \\
\hline F. & Respondent unable to co-operate & 25 & 0.8 & 14 & 0.3 \\
\hline G. & Respondent unavailable & 142 & 4.3 & 33 & 0.6 \\
\hline H. & Refusals & 628 & 18.9 & 601 & 10.9 \\
\hline I. & No contacts & 365 & 11.0 & 587 & 10.6 \\
\hline $\mathrm{J}$. & Other non responses & 619 & 18.6 & 0 & 0.0 \\
\hline K. & No. of achieved interviews & 1360 & 40.8 & 3026 & 54.7 \\
\hline L. & Co-operation rate: $\mathrm{K} /(\mathrm{H}+\mathrm{K})$ & & 68.4 & & 83.4 \\
\hline M. & Contact rate: $\mathrm{K} /(\mathrm{G}+\mathrm{I}+\mathrm{K})$ & & 72.8 & & 83.0 \\
\hline N. & Field response rate: $\mathrm{K} / \mathrm{E}$ & & 43.3 & & 71.0 \\
\hline O. & Response rate: $\mathrm{K} /[\mathrm{A}-(\mathrm{B}+\mathrm{C})]$ & & 43.3 & & 55.5 \\
\hline
\end{tabular}

Source: ESS I, ESS II (Institute of Sociology AS CR, ESS).

hundred of the selected addresses (row D). If we take this fact into account, the response rate achieved during fieldwork, as the estimate shown in row $\mathrm{N}$ reveals, was $71 \%$.

Based on experience from the ESS I, preparations for the second wave anticipated a low response rate and the size of the initial ESS II sample was designed to accommodate this expectation. The better than expected response rate achieved in the second wave meant that some of the addresses could not be used. This was because the budget for the ESS II would not have covered the expense involved in conducting the additional interviews and processing the resulting data. In fact, in the ESS II the largest proportion of the recorded non-response (as shown in rows $\mathrm{D}$ and F-J in Table 1) stemmed from the underestimation of the actual response rate in the preparation of the survey. This underestimation error accounted for more than $21 \%$ of the survey sample and was paradoxically a product of the success of rather than any failure in the fieldwork.

The standard definitions of the indicators of response and non-response rates [AAPOR 2006; Groves 2004: 135-145] do not take this kind of unusual er- 
Figure 4. Cooperation and contact rates in ESS and ISSP surveys (1997-2005) in the Czech Republic (\%)

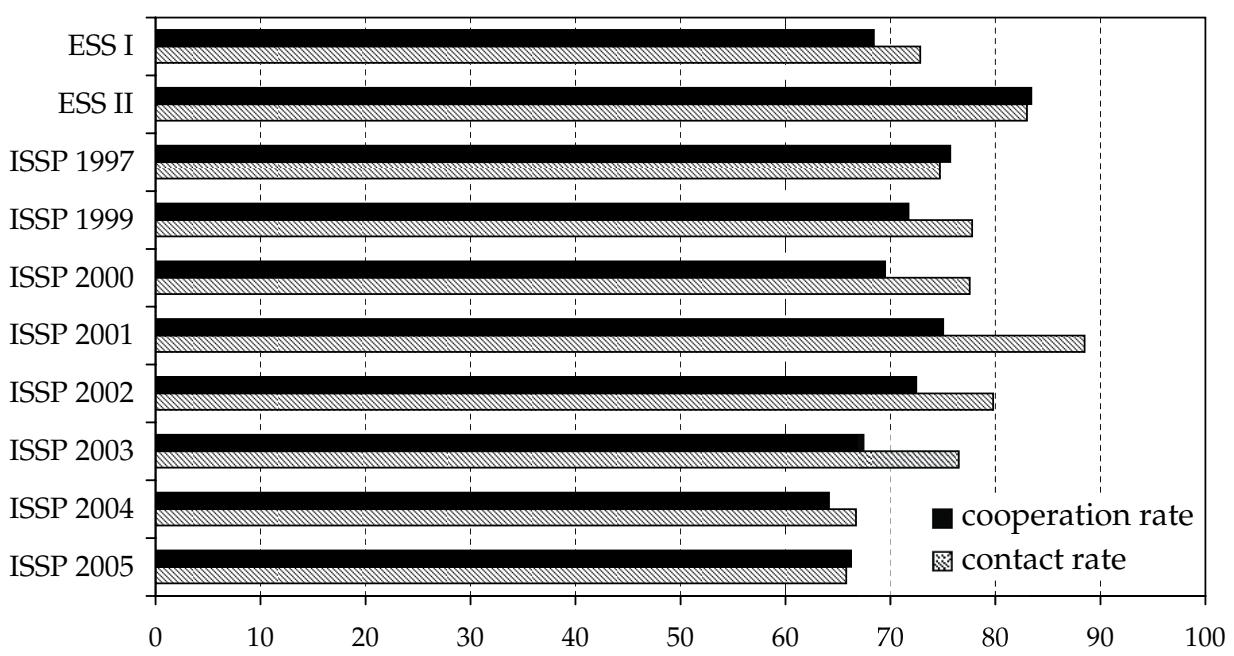

Note: For additional information on ISSP surveys, see the appendix. The ISSP (1998) is not included owing to missing information on non-contacts.

Source: Sociological Data Archive, ESS I, ESS II (Institute of Sociology AS CR, ESS).

ror into account. In the case of multistage stratified sampling it is a questionable practice to eliminate any selected units after the sample has been drawn, especially during the interviewing stage, even if we assume that the decision of which addresses to use and which to eliminate was made randomly. That is why in the overall evaluation of the quality of the data from the ESS II the Czech Republic is not ranked among the countries with a response rate of at least $70 \%$. The unused addresses are included under non-contacts in the calculations for this indicator [see Pleyser and Billiet 2006].

However, it is also misleading to evaluate the contact rate including the unused addresses, when no attempt was ever made at contacting respondents at these addresses. Therefore, a deeper analysis of non-response and conclusions on the ability to contact respondents and the willingness of the public to cooperate should be based on the responses the survey actually achieved in the field. In the following analysis we will focus mainly on outcomes achieved during the fieldwork. Pleyser and Billiet [2006] proceeded similarly in their analysis of the quality of the ESS international data file and did not include the unused addresses in the evaluation of non-contacts and refusals.

As Figure 1 shows, the field response rate of $71 \%$ in the ESS II greatly exceeded the response rates attained in contemporary Czech academic surveys and 
is closer to the results achieved in the Labour Force Survey (shown in Figure 3). Equally importantly, this evidence demonstrates that the survey climate is not as unfavourable as it is feared to be. The data presented in row L of Table 1 show that the cooperation rate in the ESS II was $83.4 \%$. Compared to the ESS I this represents an increase of almost 15 percentage points. Moreover, if we examine Figure 4 we see that this rate is significantly higher than the cooperation rates for all ISSP surveys since 1997.

The evidence presented in row $\mathrm{N}$ of Table 1 reveals that the ESS II had a higher contact rate than its predecessor. Moreover, Figure 4 reveals that the contact rate in the ESS II is also relatively high when compared to the results of other Czech academic surveys.

It is interesting to look at the number of non-contacts in relation to other forms of non-response and in relation to the interviews conducted. The non-contact rate was $13.6 \%$ in the ESS II, which is the highest percentage of non-contacts among the countries that took part in the survey. Pleyser and Billiet [2006: 15] ascribe this to the complicated sampling procedure. If we compare the ESS II with recent ISSP surveys, which are characterised by relatively simple sample designs, we see that Czech surveys often have high non-contact rates. Such comparative evidence confirms that non-contact troubles during interviewing are part of a more general problem. However, not being able to contact potential respondents is not an insurmountable problem. This is evident from the quarterly Labour Force Surveys conducted by the Czech Statistical Office. The data presented in Figure 3 show that the non-contact rate in the LFS since 2002 has generally been below $10 \%$.

If we look at row J of Table 2 for the ESS II we see that it is also possible to completely eliminate other forms of non-response in the course of the fieldwork. According to a post-ESS I survey report written by STEM, the high number of 'other non-responses' in this survey consisted of various administrative errors made in the organisation of data collection and errors in data processing. One key problem was questionnaires not being returned by interviewers. In surveys such as the Czech Labour Force Survey, the GSS and Allbus, where data quality is an explicit goal, errors of this type rarely occur.

An international comparison also reveals differences in each wave of the Czech ESS survey. With regard to the non-response rate, the Czech survey in 2002-2003 had the third worst outcome of all countries surveyed. The Czech survey's total response rate in 2004 also ranked in the lower half of all the countries surveyed. Nonetheless, it was better than that of countries such as the UK, Germany, and Spain. However, if we examine field response rates, which better reflect the actual level of cooperation of the population, the Czech Republic was among the countries with the best results - exceeding the target level of $70 \%$. Notwithstanding the failure to accurately estimate the sample size at the outset, the strategy applied in the ESS II to enhance response rates was effective. The field response rate was increased beyond the customary level achieved in academic 
surveys in the Czech Republic and well above the international average attained in the ESS. This outcome resulted from a combination of improvements in the monitored sources of non-response - refusals, non-contacts, and other miscellaneous forms of non-response.

\section{Conclusion}

The above assessment of Czech probability surveys conducted for academic purposes since 1995 shows that response rates are a serious problem. This could be reason to question the reliability of the data on Czech society and the analyses based on these data. The differences between the response rates during the first half of the 1990s and in surveys conducted later on point to a deterioration of the survey climate during this period. There have been consistently high rates of refusals and non-contacts. The level of non-contacts recorded in the Czech Republic rank among the highest measured internationally. However, the conventional opinion that there is a declining secular trend in response rates since the mid-1990s was not confirmed by available survey evidence.

Our examination of academic surveys demonstrates that a large part of the non-response problem stems from research imperfections. Outcome rates often include a big portion of the category 'other unproductive', that is, administrative and organisational failures. Interestingly, the trend in non-contact rates fluctuates considerably. We may therefore conclude that, in addition to the unfavourable survey climate, low response rates are largely the result of factors connected with the performance of the fieldwork agency. Fortunately, these issues can often be addressed by upgrading fieldwork protocols and methodologies. We also found that it is possible to obtain substantially better outcomes in survey research. This is particularly evident in the Labour Force Survey conducted by the Czech Statistical Office and in the second wave of the European Social Survey.

Our comparison of the two waves of the ESS did not look for differences in data quality between both datasets and did not provide an evaluation of the effects of particular survey strategies on total biases. There are numerous factors connected with both waves of the ESS that were capable of producing errors. The appropriate analysis of the impact of response rate enhancement on total survey error would therefore necessarily involve not only simple comparisons of the composition of surveyed samples but also an examination of the differences between respondents and non-respondents. Unfortunately, the limited size of this article puts such an analysis beyond its scope, but the article does generate a starting point for future study. Therefore, we cannot conclude here whether the described strategy of response rate enhancement was successful in terms of survey accuracy. Nonetheless, based on the evidence provided we can point out the need to deal with the non-response problem and argue for the use of sensible and prudent survey strategies that take all types of survey error into consideration. However, such strategies often require greater effort and more investment. 
In the academic sphere traditional approaches to organising survey research have focused on sampling and related errors. But contrary to expectations, sampling design effects are not the only source of survey error. Total survey error is a complex problem and in order for us to obtain more accurate results it is necessary to focus on all of its components: sampling error, coverage error, errors of measurement and non-response error. Moreover, besides being accurate data must also be timely, coherent, accessible, comparable, and fit for use. Finally, as Groves [2004] has shown, the quality of a sample survey derives from its efficiency, that is, from the relationship between accuracy and the costs of achieving it. For all these reasons recent concepts of the quality of survey research have moved away from purely statistical approaches to accuracy toward multidimensional approaches that involve quality management of the survey process [see Biemer and Lyberg 2003].

In the Czech Republic survey non-response can be a serious obstacle to reliability. Consequently, when organising surveys it is prudent to devote some thought to how much effort should be invested in attempts to reduce it. Ignoring this problem devalues the resources expended on reducing other types of error. Successful survey research strategies require more than just formal and selective approaches to data quality enhancement. This issue is not merely a topic of importance for fieldwork agencies, but is also one of key concern for all coordinators of research projects, because it is they who formulate the methodological requirements for many probability sample surveys.

JINDŘICH KREJčí is the head of the Sociological Data Archive (SDA) at the Institute of Sociology. His research focuses on survey methodology, data quality, and the study of political attitudes. He is the editor of the book Kvalita výzkumů volebních preferenci (The Quality of Survey Research on Electoral Preferences) and the author of several articles in scientific journals and books. At the Faculty of Social Sciences of Charles University he teaches courses in survey methodology, methods of social data analyses, and data management. He has also participated in the surveys of the International Social Survey Programme (ISSP) and the European Social Survey (ESS).

\section{References}

AAPOR. 2006. 'Standard Definitions. Final Dispositions of Case Codes and Outcome Rates for Surveys.' Lenexa, KS: The American Association for Public Opinion Research. Retrieved 25 May 2007. (http://www.aapor.org/pdfs/standarddefs_4.pdf).

Allbus Datenservice. 2007. Allbus Web presentation, codebook and data download at the GESIS Zentralarchiv für Empirische Sozialforschung, Cologne. Retrieved 31 May 2007 (http://www.gesis.org/Datenservice/ALLBUS).

Baim, Julian. 1991. 'Response Rates: A Multinational Perspective.' Marketing and Research Today 19 (2): 114-120. 
Biemer, Paul P. and Lars E. Lyberg. 2003. Introduction to Survey Quality. Hoboken: John Wiley \& Sons.

Bogart, Leo. (ed.) 1987. 'The Future Study of Public Opinion: A Symposium.' Public Opinion Quarterly 51 (2: Supplement): S173-S191.

Bradburn, Norman M. 1992. 'Presidential Address: A Response to the Nonresponse Problem.' Public Opinion Quarterly 56: 391-397.

Davis, James A., Tom W. Smith and Peter V. Marsden. 2005. 'General Social Surveys, 1972-2004. Codebook Appendices.' Ann Arbor: ICPSR. Retrieved 20 October 2006 (http://www.icpsr.umich.edu; Cat. No. 6293070).

de Heer, Wim 1999. 'International Response Trends: Results of an International Survey.' Journal of Official Statistics 15 (2): 129-142.

de Leeuw, Edith and Wim de Heer. 2002. 'Trends in Household Survey Nonresponse: A Longitudinal and International Comparison.' Pp. 41-54 in Survey Nonresponse, edited by Robert M. Groves, Don A. Dillman, John L. Eltinge and Roderick J.A. Little. New York: John Wiley \& Sons.

Dillman, Don A., John L. Eltinge, Robert M. Groves and Roderick J.A. Little. 2002. 'Survey Nonresponse in Design, Data Collection, and Analysis.' Pp. 3-26 in Survey Nonresponse, edited by Robert M. Groves, Don A. Dillman, John L. Eltinge, and Roderick J.A. Little. New York: John Wiley \& Sons.

ESS. 2002. European Social Survey, Round 1: Specification for Participating Countries. European Social Survey Web. London: Centre for Comparative Social Surveys. Retrieved 16 March 2006 (http://www.europeansocialsurvey.org).

ESS. 2004. European Social Survey, Round 2: Specification for Participating Countries. European Social Survey Web. London: Centre for Comparative Social Surveys. Retrieved 16 March 2006 (http://www.europeansocialsurvey.org).

Groves, Robert M. 2004 (first edition 1989). Survey Errors and Survey Costs. Second edition. Hoboken: John Wiley \& Sons.

Groves, Robert M. 2006. 'Nonresponse Rates and Nonresponse Bias in Household Surveys.' Public Opinion Quarterly 70 (5): 646-675.

Groves, Robert M. and M. Couper. 1998. Nonresponse in Household Interview Surveys. New York: John Wiley \& Sons.

Joye, Dominique. 2004. 'Pravděpodobnostní výběry a pravděpodobnost návratnosti.' (Probability Samples and Probability of Response) Pp. 185-201 in Kvalita výzkumů volebních preferencí, edited by J. Krejčí. Prague: Sociologický ústav AV ČR.

Kaase, Max. (ed.) 1999. Qualitätskrieterien der Umfrageforschung - Quality Criteria for Survey Research. Berlin: Akademie Verlag GmbH.

Keeter, Scott, Carolyn Miller, Andrew Kohut, Robert M. Groves and Stanley Presser. 2000. 'Consequences of Reducing Nonresponse in a National Telephone Survey.' Public Opinion Quarterly 64 (2): 125-148.

Krejčí, Jindřich. 2004. 'Podmínky pro realizaci výběrových šetření v České republice.' (Conditions for Conducting Sample Surveys in the Czech Republic) Pp. 67-86 in Kvalita výzkumů volebních preferencí, edited by J. Krejčí. Prague: Sociologický ústav AV ČR.

Krejčí, Jindřich, Olga Gyarfášová, Dominique Joye, František Kalvas, Martin Kreidl, Vladimír Krivý, Daniel Kunštát, Tomáš Lebeda, Yana Leontiyeva and Klára Plecitá-Vlachová. 2004. Kvalita výzkumů volebních preferencí. (The Quality of Surveys on Electoral Preferences) Prague: Sociologický ústav AV ČR.

Lynn, Peter, Paul Clarke, Jean Martin and Patric Sturgis. 2002. 'The Effect of Extended Interviewer Efforts on Nonresponse Bias.' Pp. 149-162 in Survey Nonresponse, edited by Robert M. Groves, Don A. Dillman, John L. Eltinge and Roderick J.A. Little. New York: John Wiley \& Sons. 
Matějů, Petr. 1993. Social Stratification in Eastern Europe after 1989: Report on Data Collection for the General Population Survey in the Czech Republic. Technical Report from the Survey. Prague: Sociologický ústav AV ČR.

Merkle, Daniel and Murray Edelman. 2002. 'Nonresponse in Exit Polls: A Comprehensive Analysis.' Pp. 243-258 in Survey Nonresponse, edited by Robert M. Groves, Don A. Dillman, John L. Eltinge and Roderick J.A. Little. New York: John Wiley \& Sons.

Olson, Kristen. 2006. 'Survey Participation, Nonresponse Bias, Measurement Error Bias, and Total Bias.' Public Opinion Quarterly 70 (5): 737-758.

Philippens, Michel and Jaak Billiet. 2004. 'Monitoring and Evaluating Non-response Issues and Fieldwork Efforts in the European Social Survey.' Paper presented at the European Conference on Quality and Methodology in Official Statistics, Mainz, Germany, 24-26 May 2004. European Social Survey Web. London: Centre for Comparative Social Surveys. Retrieved 16 March 2006 (http://www. europeansocialsurvey.org).

Philippens, Michel, Geert Loosveldt, Ineke Stoop and Jaak Billiet. 2003. ‘Noncontact Rates and Interviewer Calling Strategies in the ESS.' Paper presented at the International Workshop on Household Nonresponse, Leuven, Belgium, 22-24 September 2004. European Social Survey Web. London: Centre for Comparative Social Surveys. Retrieved 16 March 2006 (http://www.europeansocialsurvey.org).

Pleyser, Stefaan and Jaak Billiet. 2006. Data Quality Assessment in ESS Round 2. Between Wishes and Reality: Closing the Gap?. European Social Survey Web. London: Centre for Comparative Social Surveys. Retrieved 2 August 2006 (http://www.europeansocialsurvey.org).

Särndal, Carl-Erik and Sixten Lundström. 2005. Estimation in Surveys with Nonresponse. Chichester: John Wiley \& Sons.

Sheatsley, Paul B. 1987. 'Comments.' Pp. S186-S187 in 'The Future Study of Public Opinion: A Symposium', edited by Leo Bogart, Public Opinion Quarterly 51 (2: Supplement): S173-S191.

Smith, Tom W. 1995. 'Trends in Non-Response Rates.' International Journal of Public Opinion Research 7: 157-171.

Smith, Tom W. 2002. 'Developing Nonresponse Standards.' Pp. 27-40 in Survey Nonresponse, edited by Robert M. Groves, Don A. Dillman, John L. Eltinge and Roderick J.A. Little. New York: John Wiley \& Sons.

Steeh, Charlotte G. 1981. 'Trends in Nonresponse Rates, 1952-1979.' Public Opinion Quarterly 45: 40-57.

Steeh, Charlotte G., Nicole Kirgis, Brian Cannon and Jeff DeWitt. 2001. 'Are They Really as Bad as They Seem? Nonresponse Rates at the End of the Twentieth Century.' Journal of Official Statistics 17 (2): 227-247.

STEM. 1996. Technická zpráva - Role vlády (ISSP 1996). (Technical Report - The Role of the Government (ISSP 1996)) Prague: Středisko empirických výzkumů (STEM).

STEM. 1999. Technická zpráva - Sociální nerovnosti a spravedlnost (ISSP 1999). (Technical Report - The Social Inequalities and Justice (ISSP 1999)) Prague: Středisko empirických výzkumů (STEM).

Stoop, Ineke. 2005. The Hunt for the Last Respondent. Nonresponse in Sample Surveys. Hague: Social and Cultural Planning Office of the Netherlands.

Stoop, Ineke, Jurjen Iedema, and Frans Louwen. 2000. 'How Different Are Nonrespondents?' Paper presented at the Fifth International Conference on Logic and Methodology: Social Science Methodology in the New Millenium, Cologne, Germany, 3-6 October 2000, papers published on CD ROM.

Tuček, Milan, Lumír Gatnar and Jindřich Krejčí. 2000. Posouzení výzkumu čtenosti v rámci multimediálního výzkumu sledovanosti médií Media projekt 2000. (Examining Research 
on Readership in a Multimedia Survey on Media Ratings of the Media Project 2000) Report for the Czech Publishers Association. Prague: Sociologický ústav AV ČR.

Zaletel, Metka and Vasja Vehovar. 1998. 'The Stability of Nonresponse Rates According to Socio-Demographic Categories.' Pp. 75-84 in Nonresponse in Survey Research, Nachrichten Spezial 4, edited by Achim Koch and Rolf Porst. Mannheim: ZUMA. 


\section{Appendix}

Basic methodological information on selected probability sample surveys undertaken in the Czech Republic, 1991-2005

\begin{tabular}{|c|c|c|c|c|}
\hline Survey & $\begin{array}{l}\text { Fieldwork } \\
\text { agency }\end{array}$ & Sampling method & Fieldwork dates & $\mathrm{N}$ \\
\hline ISJP 1991: Social Justice & STEM & 2-stage stratified & $1991,26 / 06-14 / 07$ & 810 \\
\hline $\begin{array}{l}\text { ISSP 1992: Social } \\
\text { Inequalities }\end{array}$ & STEM & 2-stage stratified & $1992,16 / 10-06 / 11$ & 1101 \\
\hline $\begin{array}{l}\text { SSVE 1993: Social } \\
\text { Stratification in Eastern } \\
\text { Europe After } 1989\end{array}$ & ČSÚ, STEM & 2-stage stratified & 1993, 03-04 & 5597 \\
\hline ISSP 1993: Environment & STEM & 3-stage stratified & $1993,20-30 / 11$ & 1005 \\
\hline $\begin{array}{l}\text { ISSP 1994: Family and } \\
\text { Gender Roles }\end{array}$ & Universitas & 3-stage stratified & 1994,09 & 1024 \\
\hline $\begin{array}{l}\text { ISSP 1995: National } \\
\text { Identity }\end{array}$ & Amasia & 3-stage stratified & $1995,28 / 10-27 / 11$ & 1111 \\
\hline ISJP 1995: Social Justice & STEM & Random walk & $1995,15 / 09-29 / 10$ & 1246 \\
\hline $\begin{array}{l}\text { ISSP 1996: Role of the } \\
\text { Government }\end{array}$ & STEM & 3-stage stratified & $\begin{array}{c}1996,20-31 / 10 \\
21 / 11-31 / 12\end{array}$ & 1100 \\
\hline $\begin{array}{l}\text { ISSP 1997: Work } \\
\text { Orientations }\end{array}$ & STEM & 3-stage stratified & $\begin{array}{c}1997,15-30 / 09, \\
21 / 10-7 / 11 \\
21 / 11-31 / 12\end{array}$ & 1080 \\
\hline $\begin{array}{l}\text { ISSP 1999: Social } \\
\text { Inequalities and Justice }\end{array}$ & STEM & 2-stage stratified & $\begin{array}{c}1999,18 / 01-01 / 02, \\
06 / 02-24 / 02\end{array}$ & 1834 \\
\hline ISSP 1998: Religion & SC\&C & 3-stage stratified & $1999,18 / 06-27 / 07$ & 1223 \\
\hline ISSP 2000: Environment & SC\&C & 3-stage stratified & $\begin{array}{c}2000,01 / 10-13 / 11, \\
21 / 11-20 / 12\end{array}$ & 1244 \\
\hline $\begin{array}{l}\text { ISSP 2001: Social } \\
\text { Networks }\end{array}$ & $\mathrm{SC} \& \mathrm{C}$ & 3-stage stratified & $2001,06 / 10-05 / 11$ & 1200 \\
\hline $\begin{array}{l}\text { ISSP 2002: Family and } \\
\text { Gender Roles }\end{array}$ & SC\&C & 3-stage stratified & $2002,16 / 09-14 / 10$ & 1289 \\
\hline $\begin{array}{l}\text { ISSP 2003: National } \\
\text { Identity }\end{array}$ & $\mathrm{SC} \& \mathrm{C}$ & 3-stage stratified & $2003,26 / 09-19 / 10$ & 1276 \\
\hline ISSP 2004: Citizenship & SC\&C & 3-stage stratified & $2004,27 / 09-29 / 10$ & 1322 \\
\hline $\begin{array}{l}\text { ISSP 2005: Work } \\
\text { Orientations }\end{array}$ & $\mathrm{SC} \& \mathrm{C}$ & 3-stage stratified & $2005,16 / 05-06 / 06$ & 1226 \\
\hline
\end{tabular}

Note: This information refers to the surveys represented in Figure 1. All surveys used face-to-face interviewing. ČSÚ = Czech Statistical Office.

Source: Sociological Data Archive, Institute of Sociology AS CR. 